\title{
Didacticidad e interacción: estudio de un corpus oral de aulas de primaria*
}

\author{
Didacticity and interaction: study of an oral corpus in primary \\ school classroom
}

AINA MONFERRER / ISABEL RÍOS

UNIVERSITAT JAUME I

Recibido: $12 / 02 / 2914$

Aceptado: 30/03/2014

ABSTRACT: In this paper we investigate the characteristics of the process that allow the exportation of some scientific concepts from a scientific field to another discursive community far from the scientific sphere. By focusing on the context of the primary school classroom, we analyze the oral discourse that is constructed in the class through interaction, intended to make students understand a number of scientific and technical concepts (heart, electricity, etc.). We study which ones aret he divulgative mechanisms related to interaction that lead to the assimilation of such knowledge, from a corpus of transcripts of oral classroom discourse.

Keywords: learning, determinologization, divulgation, interaction, orality.

RESUMEN: En este trabajo indagamos las características del proceso por el que unos conocimientos científicos llegan a una comunidad discursiva externa al ámbito de la ciencia. Centrándonos en el contexto del aula de educación primaria, analizamos el discurso oral que se construye en la clase mediante la interacción, destinado a hacer que los alumnos comprendan una serie de conceptos y de procesos técnicos y científicos (el corazón, la electricidad, etc.). Estudiamos los mecanismos divulgativos de carácter interactivo que conducen a la asimilación de dichos conocimientos, a partir de un corpus de transcripciones de discurso oral en el aula.

Palabras clave: aprendizaje, desterminologización, divulgación, interacción, oralidad.

(*) Este trabajo se inscribe en el marco del proyecto de investigación «El discurs divulgatiu en català i en espanyol: gèneres, estils i estratègies argumentatives en la gestió social dels coneixements» (UJI-Fundació Bancaixa PI1B2011-53). 


\section{Introducción}

\subsection{Divulgación del conocimiento científico: el discurso académico}

El mundo de la ciencia parece a veces críptico para aquellos que no forman parte de una comunidad científica especializada. Con esto, los miembros de dichos reductos hermenéuticos logran un poder y un estatus social que reside en el conocimiento sobre ese tema que es inaccesible para el resto de la sociedad. Entonces aparece lo que se conoce como la figura del experto, tan prestigiada socialmente y presente en los medios de comunicación (Beacco y Moirand 1992). Sin embargo, no se puede olvidar que el acceso al conocimiento y a la cultura es un derecho necesario en cualquier sociedad democrática y avanzada. Por ello, surge la necesidad de hacer accesibles los lenguajes de especialidad, es decir, el discurso científico prototípico, para que cualquier persona tenga acceso a ese conocimiento, especialmente en una sociedad como la actual llamada sociedad de la información. Esto es posible gracias a la gestión social del conocimiento, que es el proceso por el cual los saberes científicos se democratizan y llegan al grueso de la sociedad.

Para que los conocimientos científicos y de especialidad lleguen a las diferentes comunidades discursivas, se necesita la intermediación de lo que llamamos mecanismos de divulgación del conocimiento, que participan en los procesos de desterminologización. Entre estos mecanismos encontramos definiciones, paráfrasis, ejemplificaciones, metáforas, repeticiones, comparaciones y analogías, literaturizaciones, juegos de palabras y también preguntas. Estos procesos de divulgación aparecen en esferas sociales muy diversas (los medios de comunicación, el discurso médico, el discurso político, los contextos educativos, etc.) y mediante canales y códigos igualmente variados.

Los rasgos característicos del discurso científico prototípico son la precisión, la congruencia y la explicitud. Es cierto que el discurso científico prototípico solo aparece en unos géneros textuales muy concretos, como un manual de cuarto curso de ingeniería industrial, o un artículo de una revista científica especializada. En cambio, los géneros textuales científicos no prototípicos, es decir, que no son puros sino que se encuentran hibridados con otros tipos de discurso, son mucho más comunes. El siguiente esquema, que visualiza la propuesta de Salvador (2000 y 2004), muestra la relación entre el discurso científico prototípico y sus discursos periféricos (huelga decir que en este esquema las categorías a veces se solapan): 


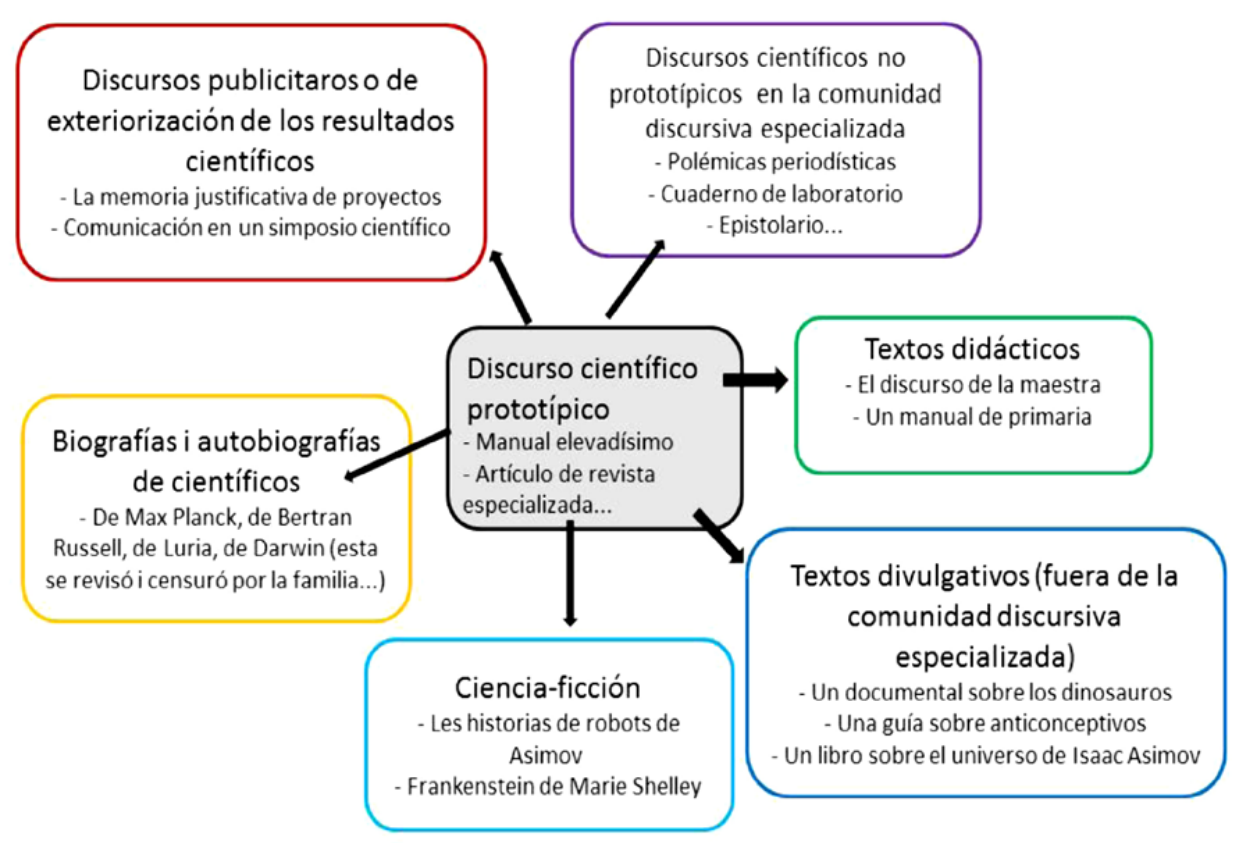

Figura 1: Esquema sobre el discurso científico prototípico y los discursos científicos periféricos

La gestión social de los conocimientos juega un papel clave en la divulgación científica prototípica que, por sus características, es inaccesible para toda persona ajena a los elevados reductos científicos especializados. En este paso de un conocimiento encriptado a un conocimiento también científico pero accesible a toda la sociedad, entran en juego tres mecanismos: la simplificación de las redes conceptuales, la reelaboración verbal del discurso y la recontextualización.

En este trabajo buscamos cuáles son las características del proceso por el que un conocimiento científico llega a una comunidad discursiva de fuera del ámbito de la ciencia. En concreto, nos centraremos en el contexto de las aulas de educación primaria. A parte de los mecanismos de desterminologización más generales que acabamos de citar y que actúan en todos los ámbitos donde aparecen los discursos científicos no prototípicos, el ámbito académico tiene sus propias especificidades. En este sentido, es exclusivamente en el ámbito académico -y especialmente en los primeros niveles-donde se enseña a los 
alumnos una serie de operaciones cognitivas indispensables para acceder a los conocimientos técnicos y de especialidad.

Además, es en la escuela donde los alumnos aprenden a descifrar y, en segunda instancia, a utilizar los géneros textuales propios del discurso científico prototípico. Los alumnos aprenden a hablar en un lenguaje técnico, saben cómo se hace una definición (al menos saben lo que suena bien y lo que no, reconociendo de forma intuitiva las formas adecuadas), saben que cuando hablan o escriben sobre ciencia en el colegio con corrección tienen que evitar coloquialismos, palabras demasiado laxas semánticamente, contradicciones, etc. En resumen, como veremos, el discurso científico no prototípico del ámbito educativo se caracteriza por el hecho de que, además de hacer llegar unos conocimientos a priori crípticos como los de la ciencia a través de mecanismos de desterminologización, será en el ámbito académico donde el alumno aprenderá a utilizar de manera consciente y efectiva las operaciones cognitivas necesarias para acceder a los conocimientos más abstractos y complejos.

\subsection{Metodología de la investigación}

Este artículo deriva de un estudio sobre el discurso oral, que se construye en la clase a partir de la interacción, destinado a hacer que el alumnado comprenda una serie de conceptos y de procesos técnicos y científicos (el corazón, la electricidad, etc.). Nos hemos centrado en el análisis de los mecanismos lingüísticos y de interacción que lo permiten, a partir de un corpus de transcripciones de discurso oral en el aula. Concretamente, analizaremos dos transcripciones de la interacción maestro-alumnos que acontece en el seno de un proyecto de trabajo globalizado: el primero trata sobre el corazón y es de segundo curso de primaria (Altava et al., 2010), mientras que el segundo, de sexto curso, versa sobre la energía (Altava et al., 2012b).

Hemos llevado a cabo un análisis exhaustivo de la transcripción con el objetivo de identificar los mecanismos de divulgación del conocimiento científico que aparecen. Con este análisis pretendemos avanzar en el conocimiento de cuáles son y cómo se desarrollan estos mecanismos concretos en el ámbito académico. También, desde un punto de vista comparativo, nos hemos aventurado a analizar las posibles diferencias de uso de dichos mecanismos en diferentes momentos de la educación primaria, concretamente entre el primer ciclo y el tercero de dicha etapa. 


\section{Análisis de los mecanismos de divulgación del conocimiento científico en el ámbito académico}

\subsection{Mecanismos de desterminologización}

a) Definiciones prototípicas

La definición es un mecanismo típico de acceso al conocimiento científico en el ámbito educativo. Los libros de texto están llenos de definiciones que tradicionalmente los alumnos han tenido que aprender y algunas de las cuales permanecerán en su memoria para toda la vida. Por ejemplo, el viento es el aire en movimiento, el sustantivo es el núcleo del sujeto o una península es una porción de tierra rodeada por todos los lados de agua menos uno, llamado istmo. Además, los diccionarios están llenos de definiciones y a ellos recurren los alumnos cuando buscan el significado de un concepto desconocido. Sin embargo, que un alumno sepa de memoria una definición no quiere decir que entienda un concepto. A veces, el alumno pregunta y el profesor define, sin que sea esta la manera más productiva a priori de aprovechar las definiciones para el aprendizaje:

Pasqual: Què és matèria?

Maestro: Perdó, pareix que m'he enganyat. Matèria és tot allò de què estan fetes les coses. [...] (Altava et al., 2012b: 92)

El aprendizaje de conceptos científicos en el ámbito escolar requiere un camino de ida y vuelta. Del concepto más técnico, abstracto y descontextualizado se pasa al ámbito conocido por los alumnos, que no es otro que el de su propia experiencia cotidiana, para retornar finalmente al concepto abstracto inicial, es decir, a la definición, pero esta vez ya entendida por los alumnos. En otras palabras, el docente tiene que ayudar a los alumnos a recorrer este camino de aprendizaje que consiste en contextualizar en su propio campo empírico el concepto científico para poderlo entender, pero además, tiene que guiarlos en el camino de vuelta hacia el conocimiento abstracto, considerado descontextualizado. Solo en este último estadio de descontextualización y de abstracción se podrá decir que el alumno ha acabado de interiorizar el concepto. Sin embargo, hay alumnos que se quedan en la fase intermedia de contextualización y no logran finalizar el proceso. Esto se demuestra cuando los alumnos son incapaces de definir de manera técnica o abstracta el concepto en cuestión.

Por lo tanto, partimos de la idea de que no se entiende un concepto si no se es capaz de explicarlo, y para explicarlo se podrían utilizar palabras pro- 
pias. Sin embargo, esto no sería suficiente en el ámbito educativo, ya que se está preparando a los alumnos para que sean capaces, en última instancia, de descifrar el discurso científico prototípico y también de saber producirlo. En este sentido, hemos observado un procedimiento por el que el alumno define un concepto en sus propias palabras y el profesor lo va corrigiendo y añadiendo tecnicismos, que mostramos en el siguiente ejemplo a propósito de la definición de fuentes de energía (Altava et al., 2012b: 93):

Blanca: És tot allò...

Maestro: Les fonts d'energia no és tot allò.... és algo concret, no podem dir tot allò.

Pasqual: És algo en el medi ambient.

Maestro: Sí, és algo en el medi ambient i tot allò que es troba en el medi ambient, què ón?... Recursos com?

Ainhoa: Naturals.

Maestro: Molt bé! Són recursos naturals, baix fiquem... baix de font d'energia fiquem... són recursos naturals a partir dels quals obtenim fonts d'energia, està clar?

Por cuestiones de fluidez del discurso y de escasez de tiempo, hay veces que el maestro no demanda al alumno la explicación científica del concepto y permite, en cambio, una definición más coloquial (2012b: 94):

Maestro: Val! Fiquem renovables a l'esquerra, i no renovables a la dreta. I què és renovable? Pasqual. Què són renovables?

Pasqual: Les coses que no s'esgoten.

Maestro: Molt bé! Les coses que no mai s'esgoten, val? Que es regeneren contínuament. Quines coses, recursos naturals no s'esgoten i es regeneren contínuament?

\section{b) Paráfrasis}

Entendemos por paráfrasis el proceso que consiste en repetir una idea o concepto (que puede ser una definición) en otras palabras, pero con un significado equivalente, aunque, según el DRAE, también se considera paráfrasis la «explicación o interpretación amplificativa de un texto para ilustrarlo o hacerlo más claro o inteligible». En el sentido de paráfrasis como ampliación, hemos visto que en el corpus $2012 b$ el profesor reformula las respuestas incompletas de los alumnos y aporta los elementos que faltan en la formulación verbal del 
concepto, de manera que el conocimiento se va construyendo de forma cooperativa y guiada por el maestro (2012b: 86$)$ :

Maestro: Vale. Para ahorrar papel sustituir el papel por toallas que te puedes traer de casa. Porque, ¿qué problema trae consigo el uso de mucho papel?, ¿qué problema medioambiental?...

Pau: Que los bosques los talan.

Maestro: Muy bien, que para producir, realizar papel, ese papel que no es reciclado, porque también se puede utilizar papel a partir de papel reciclado; si no es reciclado necesitamos muchos árboles ¿eh? Por tanto, se tala mucho ¿De qué más se habló?

También en el siguiente ejemplo el maestro parafrasea la definición del alumno para completarla, ya que el procedimiento metonímico de definición utilizado por el alumno no aporta la información suficiente para explicar, en este caso, el concepto de climograma:

Maestro. A ver, ¿vosotros os acordáis el año pasado de los climogramas? ¿Qué se representaba en los climogramas? ¿Alguien se acuerda? Eran unos gráficos en los que se representaba ¿el qué?

A. Los grados y los meses.

M. Se representaba la temperatura media de cada uno de los meses y las precipitaciones de cada uno de los meses ¿de acuerdo?

Además, el maestro lleva a cabo paráfrasis explicativas que no son de amplificación, sino que consisten en explicar lo mismo de manera distinta y más próxima a la experiencia de los alumnos para intentar que más alumnos entiendan el concepto, en este caso, el cálculo de porcentajes:

A. Calcular el $16 \%$ de 50. Dividiría 50 entre 100, y lo que me daría lo multiplicaría por 16 .

M. Es decir, con el total, con 50 partes, en este caso serían euros, con 50 euros haríamos 100 partes, y de esas cien partes cogeríamos 16 .

Repetir lo mismo mediante sinónimos es también un mecanismo del maestro para asegurarse la comprensión de un concepto por parte de los alumnos:

M. A més d'esgotar-se també contaminen, d'acord? Pues val, fiquem «no es regeneren, s'acaben, s'esgoten...» val? Tot això ho fiquem. (2012b: 97)

Por último, en relación con los conceptos de paráfrasis y de repetición, si el alumno sabe explicar un concepto técnico con sus palabras, es decir, para- 
fraseándolo, es porque lo entiende. En cambio, la mera repetición literal del concepto o de su definición no implica una comprensión del mismo.

\section{c) Repeticiones}

En el siguiente ejemplo, vemos cómo repetir lo que dice el maestro o el libro no implica necesariamente la comprensión por parte del alumno, sino la pura memorización:

M. L'energia pot canviar mitjançant transformacions. Què passa amb l'energia?

A. Transformacions. (2012b: 98-99)

Hemos observado muchos casos en los que el maestro de segundo curso se hace a sí mismo una pregunta para gestionar el flujo informativo en el discurso del aula repitiendo una partícula interrogativa, como en el siguiente caso:

M. Jo propose que posem ara com a número tres QUANT PESA. Per què? Perquè dir QUANT PESA és acabar de completar de dir com és. (2010: 89)

Uno de los mecanismos más recurrentes usados por el maestro de sexto de primaria (2012b) es la repetición. Concretamente, repite literalmente la respuesta del alumno, si es correcta, justo después de responder. Se trata de una repetición evaluativa en la que el maestro consigue al mismo tiempo dos resultados: reforzar positivamente al alumno que ha acertado y asegurarse de que lo dicho queda oficialmente aceptado, institucionalizado de alguna forma, y llega al resto de alumnos mediante la voz del experto, es decir, del maestro. A veces, se acompaña con un refuerzo positivo explícito:

A. Disminuyendo

M. Disminuyendo ¡Muy bien! (2012b: 154)

Otras veces, lo hace para demandar más información si la respuesta es incompleta:

Maestro: He gastado menos. ¿Por qué creéis que he gastado menos? A ver, ipensemos!

Irene: Porque has estado menos en casa.

Maestro: Puede ser porque he estado menos en casa. Pero por qué más.

Ainhoa: Porque el día cada vez es más largo. 
Maestro: Porque cada vez el día es más largo... ¿el día? (2012b: 155)

También abundan las repeticiones fáticas, es decir, que el maestro las hace para asegurarse que toda la clase oye las instrucciones del ejercicio:

A. El porcentaje de consumo eléctrico en la segunda semana de marzo.

M. Entonces, lo que vamos a representar en el diagrama de barras ¿qué es?... el porcentaje de consumo eléctrico en la... segunda semana de marzo. Repito, vamos a representar en un diagrama sectorial el porcentaje de consumo eléctrico diario durante la segunda semana de marzo ¿vale?

\section{d) Alternancia de registros}

El discurso del aula de primaria se caracteriza por una fuerte alternancia de registros, derivada del esfuerzo por parte del docente de introducir el lenguaje científico, es decir, enseñar a usar el registro elevado de la lengua en un contexto donde los receptores solamente conocen el registro coloquial y un registro estándar, podríamos decir intermedio, introducido por los medios de comunicación de manera caótica y a menudo incoherente para ellos.

Entonces, el discurso del aula se convierte en una lucha continua del maestro por establecer el lenguaje culto en el aula en la medida de lo posible, en la que el docente corrige continuamente a los alumnos por el uso del lenguaje en referencia a los registros. Por otro lado, esta brecha de conocimiento lingüístico entre el maestro y los alumnos provoca a veces episodios de incomprensión que suelen pasar desapercibidos cuando el profesor introduce conceptos técnicos sin darse cuenta y muchas veces los alumnos no preguntan su significado. Para ilustrar esto último, podemos observar el uso de la palabra especular en el corpus de sexto $(2012 b$ : 48, 103). Esta palabra aparece en tres ocasiones diferentes y en ninguna de las tres es explicada por el maestro ni cuestionada por ninguno de los alumnos. Lo mismo pasa con la palabra promulgar:

M. I de què s'encarrega la Conselleria?... De fer que ens arriben els recursos però també de promulgar aquells que afecten al nostre sistema educatiu, us en recordeu, no?

En referencia al registro y al esfuerzo del maestro en el uso adecuado de este, mostramos ahora un ejemplo donde el maestro no acepta la propuesta del alumno, que usa un léxico demasiado coloquial (molinos), y lo induce al uso de un lenguaje más científico (aerogeneradores). (2012b: 94-95) 
Maestro: Però no passem... algú sap com es produeix el vent? Com es produeix el vent?

Pau: Pels molins...

Maestro: Pels molins no.

Pau: No! Pels aerogeneradors.

Maestro: Els aerogeneradors.

En el corpus de segundo curso de primaria (2010), observamos que, a diferencia de lo que ocurre en el corpus de sexto, el registro elevado de la lengua propiamente científico proviene principalmente del libro de texto, ya que el maestro se mantiene en un registro intermedio:

Maestro: Grams. Ara vaig a llegir una altra informació. «La forma -lo forma un tipo de músculo estriado, el miocardio, recubierto externamente por una membrana sedosa de doble pared; la capa adherida al músculo, constituye el epicardio y la externa, el pericardio, que fija el corazón a las estructuras- a las estructuras vecinas, pero permite la contracción». Qui ho ha entès, el que jo he dit?/Balma.

Balma: Que... el cor pesa entre tres-cents i cinc-cents grams. (2010: 74-75)

Además, es destacable en cuanto al registro que, durante toda la secuencia, esta maestra utiliza la expresión quedaría bien y quedaría mal para hacer reflexionar a los alumnos sobre si lo que están escribiendo es correcto o no desde dos puntos de vista: la adecuación temática y el estilo. El hecho de quedar bien o mal es de un registro claramente coloquial o poco científico, pero en este contexto sirve para que los alumnos, que todavía intuyen más que razonan por normas de escritura, empiecen a desarrollar esa intuición lingüística de manera lógica:

Maestro: A veure... és una bomba muscular que envia sang-. (Llig.)

Xiquet: Per.

Xiquet: Per.

Maestro: A veure-. A veure, com quedaria? Per les venes i les artèries, per tot el cos? Quedaria bé?

Xiquet: Sí.

Xiquet: Per tot el cos, eh-.

Maestro: Saül, contesta'm, quedaria bé o no?

Saül: Sí. (2010: 106-107) 
e) Fraseología

Pese a que las expresiones fraseológicas se encuentran en todos los registros y ámbitos de uso, en el registro coloquial y en la oralidad son especialmente importantes. Utilizar este tipo de expresiones a modo de eslóganes fáciles de recordar es un recurso típico en el ámbito educativo a la hora de explicar contenidos que se quiere que los alumnos recuerden a largo plazo. Por ejemplo, en el ámbito de la educación ambiental, podemos encontrar enunciados a modo de eslóganes del tipo l'aigua es un bé escás: reutilitza-la, como en el siguiente fragmento:

M. Molt bé! Hem d'estalviar aigua. No, a veure, jo he vist de vegades que algú es deixa l'aixeta oberta. Per tant, hem d'estalviar aigua, eh? És molt important, l'aigua és un bé escàs. (2012b: 103)

O bien como en el siguiente ejemplo, reglas nemotécnicas que nos permiten memorizar ciertas conductas aconsejables:

M. Per tant, s'ha de fer un ús responsable de l'aigua, de l'energia i cal aplicar la regla de les tres «r», què són Ainoha?

A. Reduir, reutilitzar i reciclar. (2012b: 104)

Con respecto a las expresiones fraseológicas coloquiales, en el siguiente ejemplo vemos cómo es el profesor quien utiliza una expresión coloquial como fer el que toque parafraseando la definición de responsabilidad que había ofrecido el alumno en términos coloquiales, para luego volver a elevar el registro con una nueva paráfrasis («aconseguir un medi ambient millor»).

M. Què és la responsabilitat?

A. El que hem de fer.

M. Fer el que toque! En aquest cas, fer per aconseguir un medi ambient millor. (2012b: 104)

\section{f) Ejemplificaciones}

Hay veces que se co-construye un concepto a través de los ejemplos de los alumnos, coordinados por el maestro. Podemos observar que entre los ejemplos, aparecen también paráfrasis y definiciones co-construidas $(2012 b$ : 106-107): 
M. Quines coses, recursos naturals no s'esgoten i es regeneren contínuament?

Anna: La biomassa.

Maestro: La biomassa! Molt bé! La biomassa. Què és la biomassa? Perquè no ho tinc massa clar. No se què és la biomassa, tu saps el què és la biomassa? Què és?

Alumno: Són... les restes d'animals morts...

Maestro: Val, no obstant, diu que són restes d'éssers vius que després es poden, cremant-los, produeixen calor, produeixen... val! No obstant, demà busqueu per a demà què és la biomassa, que no ens queda massa clar. Vinga, altres recursos naturals, Pasqual.

Pasqual: El vent...

Maestro: El vent.

Pasqual: L'aigua.

Por un lado, hemos observado que los alumnos, a veces, cuando no saben cómo definir un concepto, lo hacen a través de un ejemplo, hecho que constata un déficit en la comprensión de dicho concepto o en el lenguaje de la abstracción:

Maestro: Algú sap què és la combustió? Què és?

Alumno: Quan, per exemple, el petroli s'encén. (2012b: 96)

Por último, hemos observado que en los dos corpus se hace uso reiterado de un mecanismo de construcción del conocimiento que consiste en que el maestro recurre a ejemplos cercanos a la experiencia del alumno para que entienda un concepto abstracto. Se trata de la contextualización a través de ejemplos como mecanismo de construcción del conocimiento. Por ejemplo, cuando el maestro de sexto curso trata de explicar qué son los residuos hablando de los restos del almuerzo que ensucian el patio del colegio (2012b: 87$)$ :

Maestro: Y ¿os dais cuenta? Yo el año pasado, cuando veíamos las papelera, raro era el día que no veíamos siete $u$ ocho bolitas de papel de aluminio, si os dais cuenta ahora no hay ninguna. ¿Por qué? Porque desde el colegio mentalizamos a los niños para que el almuerzo lo traigan en bolsitas de plástico que se pueden reutilizar o en papel ¿vale? Pero desde el consejo se está intentando a ver si alguien subvenciona unas bolsitas de tela ieh? Para traer el bocadillo en ellas y poderlas reutilizar constantemente, cuando se ensucian se lavan y ya está. ¿De qué más se habló? 
g) Narrativizaciones

En el ejemplo anterior, observamos que, más que describir unos hechos científicos, se narra una situación, se cuenta una historia. Las secuencias textuales preferentes del discurso científico prototípico son la descriptiva, la expositiva y la argumentativa, pero no la narrativa. Por tanto, podemos afirmar que en el paso del discurso científico prototípico a la divulgación cambian los géneros y las secuencias textuales, y es en este proceso donde aparecen las secuencias narrativas.

En el corpus analizado, hemos detectado varios ejemplos de un recurso que consiste en una secuencia narrativa de un ejemplo cercano a los alumnos. Consideramos que es narrativa porque aparecen personajes y porque los tiempos verbales no son intemporales ni presentes, sino de pasado, como en el siguiente ejemplo del corpus de segundo curso (2010: 76):

A. «El corazón, un músculo hueco. Seguro que en más de una ocasión has sentido, al colocar la mano en tu pecho, los latidos de tu corazón y te has preguntado el porqué de sus palpitaciones, vamos a estudiar cómo es [ahora continua con un lenguaje más científico, enumeración de términos técnicos: aorta, ventrículo, aurícula...]».

h) Comparaciones y metáforas

Desde una perspectiva lingüística, podemos definir la metáfora como una comparación implícita. En las tres intervenciones de alumnos de segundo que mostramos a continuación donde se intenta definir el corazón, observamos que comparación, definición y metáfora son elementos estrechamente relacionados:

a) [lee] «El corazón es una bomba muscular de tamaño de un puño». (2010: 70)

b) Xiquet: El cor és- és és com un- una forma d'un puny tancat. (2010: 112)

c) Xiquet: El cor, el cor té forma de puny. (2010: 112)

Pese a que la metáfora es una de las herramientas más potentes para la comprensión de los conceptos científicos, no todas las metáforas son válidas en todos los contextos. Para que una metáfora funcione como herramienta cognitiva efectiva tiene que formar parte del universo de conocimientos previos del receptor. En el corpus de segundo curso (2010), observamos un desajuste 
en la metáfora que subyace a la definición básica del corazón: EL CORAZÓN ES UNA BOMBA MUSCULAR.

De los diversos significados del significante bomba, el más elemental y famoso entre los niños el de objeto que explota. En cambio, el significado que subyace a esta definición es el de mecanismo para impulsar de manera mecánica y continuada un líquido, y este segundo significado, más complejo, no suele formar parte de los conocimientos enciclopédicos de un niño de segundo de primaria. Por tanto, en este punto se produce un desajuste entre maestro y alumnos que impide la comprensión, hecho que hemos constatado por dos vías.

Por una parte, porque los alumnos no encuentran otras palabras que las de la definición del libro para explicar dicho concepto (2010: 71):

Maestro: A vore, de tot el que he llegit d'Antoni, què heu entès?/Balma.

Balma: Que jo he entès que- que- que han dit que el cor és una bomba mus-

cular que fa circular la sang.

Por otra, porque un alumno afirma que el corazón es una bomba muscular que «bombardeja» (2010: 97) la sangre por todo el cuerpo, a lo que una compañera le corrige diciendo que envía sangre. El hecho de confundir bombear con bombardear indica claramente que la metáfora del corazón como una bomba no está funcionando como elemento aclaratorio, sino como elemento que añade confusión y complica todavía más la comprensión del término. Es un ejemplo de cómo la aplicación de una metáfora que no se adecúa al nivel de los alumnos dificulta la comprensión en vez de facilitarla.

En el mismo corpus de segundo de primaria se recoge el discurso oral de una actividad didáctica sobre el corazón, donde el maestro guía a los alumnos para escribir un texto jerárquico donde se explique qué es el corazón. Con este proceso se consigue que, al mismo tiempo que el alumno asimila unos contenidos, se familiarice con la metáfora ontológica del espacio físico por el espacio conceptual necesario para la comprensión de conceptos científicos complejos. Así, el alumno aprende a visualizar mentalmente las redes conceptuales complejas que le sirven para entender el funcionamiento del corazón y que le sirven de base para futuros conocimientos abstractos (2010: 89):

Marc: Jo he dit- per- per- jo he dit/QuÈ FA? Per- perquè si si- han- si hem-.

Maestro: A vore, per què? Per què has posat QUÈ FA?

Marc: Perquè si hem ficat les dos un a dalt i un dos baix, tindríem- tindria que anar QUÈ FA?

Maestro: Ja està!/Val, Almudena! Tu per què, QUANT PESA? 
Almudena: Perquè- // quiero saber qué- qué cantidad tiene de sangre- paporque, si tiene poca, no podría repartirla y si tiene mucha podría repartirla a todo el cuerpo.

\subsection{La construcción guiada del conocimiento}

\subsubsection{La reflexión metacognitiva}

En relación con este último ejemplo, podemos ver que los alumnos interiorizan esta manera cientifica de relacionar conceptos y de jerarquizarlos, como en el siguiente caso, donde una alumna reflexiona en voz alta sobre este tipo de organizaciones abstractas. $\mathrm{Y}$ es que aprender a clasificar y a jerarquizar es indispensable para la comprensión de conceptos abstractos (2010: 88):

\footnotetext{
Maestro: COM FUNCIONA?/Va, expliqueu als vostres companys per què després de COM És? Voleu proposar el que proposeu.

Maestro: Balma.

Balma: Jo he- he proposat COM FUnCIOnA? Perquè crec que tin- tindria que anar des- després que de COM És? COM FUNCIONA?/Crec que tindria que anar COM FUNCIONA?
}

La característica más importante del discurso científico periférico que se genera en el aula de primaria es la interacción y la co-construcción del conocimiento. Hemos dicho antes que la escuela es la principal encargada de, además de divulgar la ciencia, aportar a los alumnos las herramientas cognitivas necesarias para hacer ciencia y para poder, en última instancia, consumir y producir textos científicos prototípicos. En este sentido, Neil Mercer habla del discurso educado (1997: 93), que es el que utilizan los alumnos cuando están en este proceso de aprender cómo se habla de ciencia. Los alumnos tienen que aprender que la ciencia utiliza determinados géneros textuales, secuencias textuales expositivas, explicativas y argumentativas, registro formal, modalización cero, etc. Pero además, para hacer ciencia son necesarios ciertos mecanismos cognitivos que también se trabajan en el aula y que se explicitan a través del léxico (principalmente de los verbos) así como a través de reflexiones metacognitivas.

En cuanto al léxico, observamos, sobre todo en el corpus de sexto de primaria, el uso insistente de verbos y locuciones verbales relacionados con el campo de la investigación y de la búsqueda en general. Se trata del uso reiterado de verbos como averiguar, buscar, investigar, descubrir, atreverse a, 
pensar como es tal cosa, etc. Se trata de presentar los ejercicios como pequeñas tareas de indagaciones que el maestro encomienda a los alumnos; pequeñas investigaciones que ponen al alumno en el rol de científico. De esta manera, el profesor (2012b) no pone deberes en el sentido clásico de tareas de repetición o consolidación de saberes, sino que requiere tareas de búsqueda de información para casa, mucho más constructivas y significativas, a la vez que más útiles para el aprendizaje.

El siguiente ejemplo (2012b: 49) es una secuencia donde aparece el concepto científico de cogeneración. El profesor evita decir qué significa y prefiere que cada alumno lo descubra por su cuenta en casa. Además, el ejemplo es interesante porque incluye una reflexión metalingüística sobre cómo uno de los alumnos deduce el significado de la palabra a partir del prefijo que lleva (co-). El maestro explicita este proceso mental de un alumno para que el resto de la clase tome conciencia de la utilidad de este proceso de deducción:

Maestro: [...] ¿alguien sabe que es la cogeneración? Yo sí que lo sé porque me he informado pero ¿vosotros lo sabéis?... Pues tarea para mañana intentar averiguar lo que es la cogeneración, lo anotáis.

Anna: Mezclas...

Maestro: Cogeneración, mezclas. El «co-» te ha dado la idea de la mezcla ¿verdad que sí? Algo. Por ahí va, un poquitín, la cogeneración. Ahí ponéis, en la parte blanca ponéis «averiguar qué es la cogeneración».

Alumno: Mezcla de...

Maestro: Ssh! Tú lo averiguas ¿vale?

En el siguiente ejemplo vemos cómo el maestro demanda a la alumna más precisión a la hora de explicar el contenido de un diagrama sectorial, ya que una de las características del discurso de la ciencia es la precisión (2012b: 161).

M. Estábamos analizando un diagrama sectorial ¿sobre qué?

A1. Sobre lo que habíamos consumido... en el diagrama representábamos lo que habíamos consumido cada día.

M. Pero quiero que seas más precisa.

A2. Estábamos representando los kilovatios en porcentajes.

En este otro ejemplo, observamos que el maestro explicita el hecho de que la alumna ha realizado una relación mental entre conceptos de diferentes ámbitos, ya que este tipo de relaciones sinópticas son las que potencian el pensamiento científico creativo y, por tanto, los avances de la ciencia. 
A. Que hi ha vegades que la natura ens... per exemple, l'aire i l'aigua pertanyen a la natura $\mathrm{i}$ ens poden ajudar per a produir energia.

M. A vore, per exemple, l'aire i l'aigua que són inesgotables, que els tenim ahí, poden produir energia. Entonces tu ja has relacionat algo del medi ambient amb l'energia.

Y en este otro, el maestro habla de la complejidad de un concepto que está explicando, y da pie a los alumnos para que investiguen sobre él haciendo evidente la complejidad de la ciencia, que hace necesaria la dosificación de la información.

M. [explicando cómo se obtiene la energía geotérmica] Bueno, això és complicat. També podríem investigar sobre això, eh? Val!

Por otro lado, el maestro de sexto está continuamente motivando a los alumnos para que consigan una autonomía en estos procesos mentales que necesita la ciencia y que se aprenden sobre todo en la escuela. Lo hace por medio de expresiones motivacionales que incluye en los enunciados de las tareas que pide. Por ejemplo, cuando dice: ¿Tú serías capaz de abrir el diagrama de barras correspondiente al consumo diario de la primera semana? (2012b: 149); o bien en el siguiente caso, donde está fomentando la autonomía de los alumnos a la hora de realizar un ejercicio de cálculo por su cuenta:

M. Dividir entre 3,6 ¿De acuerdo? Repito, el $100 \%$ es todo el círculo, 360 grados. Ahora ¿qué tenemos que hacer? Averiguar los grados que tendrá cada sector circular para cada uno de los porcentajes ¿de acuerdo? Pues eso me lo hacéis vosotros solitos ya, a partir de ahora. Me pasáis los porcentajes a los grados multiplicándolo por lo que ha dicho Anna, 3,6. (2012b: 164-165)

\subsubsection{Las preguntas}

Las preguntas son el elemento clave de la construcción guiada del conocimiento, ya que son el recurso verbal más directo para pedir la interacción del interlocutor. Además, las preguntas son un elemento clave que, usado en el aula, permite al maestro gestionar el flujo informativo de manera equilibrada y controlarlo para adaptarlo al nivel de sus alumnos. Las preguntas permiten recapitular, abrir nuevos temas, fomentar la participación de los alumnos en cada caso, cerrar puntos, controlar la atención y la recepción de los alumnos, puntualizar, ejemplificar, etc. 
Por todo esto, consideramos que las preguntas son la herramienta fundamental para gestionar la efectiva adquisición de conocimientos científicos por parte de los alumnos. A causa de las características del corpus analizado, que son transcripciones orales que muestran secuencias de interacción maestroalumnos, y también por cuestiones de espacio, nos centraremos en la clasificación de las diferentes funciones de las preguntas del maestro y de los alumnos en el proceso de divulgación del conocimiento científico en el aula de primaria, dejando de lado otras preguntas no relacionadas con el contenido científico.

\subsubsection{DEL DOCENTE}

Hemos identificado ocho tipos diferentes de preguntas hechas por el maestro relacionadas con la construcción guiada del conocimiento: preguntas fáticas, imperativas, retóricas, recapitulativas o indagatorias (que pueden ser de desconocimiento fingido), para incentivar la participación, sobre conocimientos previos, preguntas cerradas sobre contenidos y preguntas abiertas sobre contenidos. A continuación, explicaremos brevemente cada tipo con algunos ejemplos del corpus.

Las preguntas fáticas, como su nombre indica, sirven al maestro para asegurarse de que los alumnos lo están escuchando y comprenden lo que está explicando. Preguntas del tipo ¿vale? y ¿de acuerdo? son muy comunes en los dos corpus analizados. Se trata de preguntas fáticas, que sirven al maestro para comprobar que los alumnos atienden a sus explicaciones. Normalmente se colocan al final de una explicación teórica o de una instrucción, como podemos comprobar en el siguiente ejemplo:

Maestro: Vale. Y los resultados de esa encuesta en la semana verde tienen que quedar expuestos ¿vale? Entonces, los responsables de representar en diagramas sectoriales, los porcentajes en cada una de las respuestas, somos nosotros, los alumnos de sexto. Los alumnos de sexto nos encargaremos de recopilar todos los datos de todas las clases ¿eh? Y elaborar diagramas sectoriales sobre los porcentajes ¿eh? De cada una de las respuestas de cada una de las preguntas ¿Quieres leer las preguntas, por favor? Primer apartado, lees el primer apartado. (2012b: 88)

La última de las preguntas que aparecen en este ejemplo es imperativa, ya que demanda una tarea a un alumno. En este caso, leer las preguntas. También hay preguntas fáticas más desarrolladas, como: P. «Per què fas mala cara, Carles?», R. «Perquè no entenc casi res» (2010: 71). Además de las preguntas fáti- 
cas, que a veces se convierten en muletillas de algunos maestros, las preguntas retóricas son también muy abundantes y se usan para gestionar la información. De hecho, con este tipo de preguntas, se avanza a las hipotéticas dudas que deduce que tendrán sus alumnos sobre el contenido explicado:

Maestro: Y ¿os dais cuenta? Yo el año pasado, cuando veíamos las papeleras, raro era el día que no veíamos siete u ocho bolitas de papel de aluminio, si os dais cuenta ahora no hay ninguna. ¿Por qué? Porque desde el colegio mentalizamos a los niños para que el almuerzo lo traigan en bolsitas de plástico que se pueden reutilizar o en papel ¿vale? Pero desde el consejo se está intentando a ver si alguien subvenciona unas bolsitas de tela ¿eh? Para traer el bocadillo en ellas y poderlas reutilizar constantemente, cuando se ensucian se lavan y ya está. ¿De qué más se habló? (2012b: 87)

En este fragmento observamos distintos tipos de preguntas: un «¿por qué?» retórico, un «¿os dais cuenta?» también retórico porque no espera respuesta, dos interrogaciones fáticas $\mathrm{y}$, por último, una pregunta de recapitulación. Las preguntas de recapitulación y las preguntas indagatorias sirven al maestro para estimular la participación de los alumnos: «¿de qué más se habló?», «Estaria tot?», «¿por qué más?», «¿se nos ocurre algo más?», «algú proposa una altra? Almudena?». En este último caso, se interpela directamente a una alumna para que participe. A veces, en este tipo de preguntas, el maestro finge que no sabe algo, como ocurre en el siguiente ejemplo con el concepto de biomasa:

Maestro: La biomassa! Molt bé! La biomassa. Què és la biomassa? Perquè no ho tinc massa clar. No se què és la biomassa, tu saps el què és la biomassa?

Què és? (2012b: 94)

También hay preguntas de comprobación de los conocimientos previos. En este caso, el maestro busca ejemplos en contexto real: «¿Quién ha visto diagramas en algún sitio además de en el cole?» (2012b: 157). Hay también preguntas que incentivan la participación, del tipo «¿tú te atrevirías a...?».

Finalmente, existen las preguntas sobre conocimientos declarativos, que en principio no admiten duda. Estas pueden ser cerradas, como «Però la sang és blava?» (2010: 102) o abiertas, como «I per què es veu més blava?» (idem). La función de estas preguntas que el maestro dirige a todos los alumnos o a uno de ellos es hacerles reflexionar sobre un contenido para comprobar si lo han entendido.

Antes hemos dicho que el proceso de adquisición de un concepto científico consiste en un camino de ida y vuelta. Durante la ida (cuando se contextualiza el concepto mediante los mecanismos de desterminologización) el alumno 
descifra el concepto. En el camino de vuelta (cuando ya es capaz de entender el concepto abstracto), el alumno interioriza el concepto. El maestro puede comprobar si el alumno ha realizado este camino de doble sentido si es capaz de explicar el concepto de manera técnica pero sin calcar la definición del manual. Este lenguaje abstracto y técnico que el alumno ha adquirido es lo que Neil Mercer llama discurso educado (1997: 93).

En este sentido, hemos analizado las maneras de contestar a las preguntas ¿qué es $\mathrm{x}$ ? $\mathrm{y}$ ¿qué quiere decir $\mathrm{x}$ ? que aparecen en el corpus, $\mathrm{y}$ hemos identificado cinco tipos de respuestas: $a$ ) no saber la respuesta («Blanca: Eh... número de personas... no sé», 2012: 65), $b$ ) poner un ejemplo ([la combustió és] quan per exemple el petroli s'encén, 2012b: 96), $c$ ) hacer una comparación («el cor és com una forma d'un puny tancat» 2010: 112), $d$ ) definir el concepto de manera coloquial («renovables són les coses que no s'esgoten», 2012b: 94), y $e$ ) definir técnicamente el concepto («l'energia és tot allò que provoca els canvis al nostre voltant», 2012: 92). El último tipo de respuesta es el que más se aproxima al discurso científico prototípico, que es el modelo de lengua usado para hablar científicamente.

\subsubsection{DE LOS DISCENTES}

En cuanto a los tipos de preguntas sobre contenidos científicos que los alumnos hacen al maestro, hemos podido identificar cuatro tipos diferentes: respuestas interrogativas (que denotan inseguridad en la respuesta por parte del alumno), preguntas para situarse, preguntas para aclarar conceptos y, por último, preguntas que van más allá de los contenidos que se explican y que relacionan estos con otras esferas de conocimiento o con la experiencia cotidiana.

Las preguntas para situarse las hacen los alumnos cuando han perdido el hilo de la explicación del profesor. Son preguntas abiertas del tipo ¿por dónde vamos? o cerradas: «estem parlant de menys energia, no?» (2012b: 155). Otro tipo son las preguntas sobre el contenido de lo que se explica: «I la brutícia de tot el cos fa que les venes es vegen blaves?» (2010: 103), «A. ¿Cómo es la energía nuclear?» (2012b: 97) o «A. Com ix eixe calor? [de la energía geotérmica]» (2012b: 96). Hay preguntas de los alumnos que van más allá de los contenidos que se explican. Estas suelen ser las preguntas más interesantes y las que denotan una mayor comprensión de los contenidos, ya que el alumno es capaz de ir más allá de la comprensión básica y relacionarlos con el mundo real (ex.: «I això és bo o mal?», 2012b: 128). 
Otro tipo de preguntas de los alumnos son las que hemos llamado respuestas interrogativas. Se trata de las ocasiones en las que el alumno contesta a una pregunta con la respuesta pero con entonación interrogativa. Estas respuestas interrogativas tienen lugar cuando el alumno contesta al maestro con una pregunta porque no está seguro de su respuesta, por lo que el alumno espera la posterior reafirmación de la respuesta por parte del maestro:

Maestro: L’Ajuntament, molt bé! L’Ajuntament. Qui és el responsable màxim, el que coordina l'Ajuntament.

Alumno: L'alcalde?

Maestro: L'alcalde! L'alcalde és la màxima responsabilitat. (2012b: 106)

\section{Conclusiones}

En el corpus de sexto curso, hemos visto cómo se conceptualizaba el aprendizaje a través de la metáfora del conocimiento científico. Es importante hacer ver a los alumnos que la vida está llena de experimentos y de descubrimientos que todos podemos alcanzar desde la perspectiva del científico, para ver la ciencia como algo cercano ya desde la infancia. Hay que empoderar a los alumnos para la ciencia y mostrarles que los pequeños descubrimientos del aprendizaje son metáforas a pequeña escala del largo camino de la ciencia. Por esto es útil que el maestro conduzca a los alumnos a aprender sobre ciencia a partir de la metáfora del alumno científico.

Hemos comprobado también que el docente debe conocer en profundidad el nivel de conocimiento del que parte el alumno para aplicar de manera efectiva la desterminologización. De lo contrario, hemos visto que pueden surgir barreras en la comprensión, como pasa cuando no se explican ciertos tecnicismos o cuando se usa una metáfora basada en una imagen que los alumnos todavía no conocen.

Por otra parte, no se puede caer en el error de la excesiva simplicidad. Los conocimientos científicos se tienen que abordar en profundidad en la escuela y los alumnos han de ser conscientes de su complejidad, pero no por eso quedarse en la superficie simplista de los conceptos. Es necesario que el maestro utilice el lenguaje científico y que enseñe a los alumnos a utilizarlo también, con el objetivo final de que los alumnos lleguen algún día a utilizar autónomamente el lenguaje científico prototípico.

Los conocimientos científicos se representan en la mente dentro de marcos o módulos conceptuales. Estos lugares mentales tienen plasticidad y cambian a medida que aprendemos para poder procesar conceptos más abstractos y 
complejos como los de la ciencia. De hecho, según el modelo de redescripción representacional de Karmiloff-Smith, el desarrollo consiste en un proceso de cambio representacional (1992: 28). Por eso es indispensable valorar el papel de la escuela en el desarrollo de los marcos y procedimientos cognitivos que permiten acceder a la ciencia.

Para llegar al conocimiento científico, además de los contenidos y del lenguaje, se necesita conocer ciertos procedimientos cognitivos de abstracción: capacidad de interrelación, extrapolación, comparación, jerarquización, síntesis, deducción, inducción, etc. Es especialmente en los niveles iniciales de la educación reglada donde se aprenden este tipo de funciones cognitivas y metacognitivas indispensables para el acceso al conocimiento científico en toda su complejidad.

Entre las principales diferencias a la hora de enseñar conceptos científicos entre los dos niveles de primaria (segundo y sexto curso), de los dos corpus analizados, cabe destacar que en el corpus de segundo se observa un interés de trabajar la lengua al mismo tiempo que la ciencia que disminuye notablemente en el corpus de sexto, además de trabajar desde el punto de vista de la organización de la información sobre el concepto científico en un texto, sabiendo organizarla de más a menos importante. En cambio, en el corpus de sexto, se observa más interés por parte del profesor en operaciones matemáticas concretas y en que los alumnos manejen de manera adecuada el lenguaje científico, a un nivel mucho más específico que en el caso de segundo de primaria, donde hay más preocupación por una comprensión global de la ciencia y del concepto científico a partir de la escritura.

El docente debería esforzarse por crear en sus alumnos una construcción mental atractiva y accesible de la ciencia y de la figura de los científicos, ofreciéndoles herramientas para que puedan enfrentarse de manera autónoma a la ciencia. Por eso es tan importante trabajar en la línea del aprendizaje significativo y manejar textos reales como informes, fichas, encuestas, facturas... En definitiva, el maestro tiene que tener como objetivo crear pequeños científicos curiosos por aquello que les rodea. La escuela tiene un papel clave en la consolidación de este marco cognitivo de la ciencia en las construcciones mentales de los alumnos, pero también lo tienen los medios de comunicación y las familias. 


\section{Referencias bibliográficas}

Altava, V.; F. Gimeno; I. Ríos; I. M. Gallardo (2012): «Las preguntas, nexo entre la investigación y la enseñanza» en CARVALHO, J. A. et al. (eds.): Aula da Lingua: Interaçao e reflexao, Portugal, Óbidos: Escola Superior de Educaçao e Ciencias Sociais, 13-28.

Altava, V.; F. Gimeno; G. Lorenzo; I. Pérez; I. Ríos (2012): Situacions d'aula III. Un projecte globalitzat sobre l'energia en sisé de primària, Castelló, Universitat Jaume I. <http://repositori.uji.es/xmlui/bitstream/ handle/10234/42741/s64.pdf?sequence $=6>$ [Consulta: 19-3-2012].

- (2010): «Situació II “El cor”. L'escriptura d'un text dins d'un projecte de treball globalitzat» en Situacions d'aula II. Materials docents d'ús interdisciplinari, Castelló, Universitat Jaume I, 67-119. <http://repositori.uji. es/xmlui/bitstream/handle/10234/23981/s36.pdf?sequence $=6>$ [Consulta: 19-3-2012].

Bauman, Z. (2006): Vida líquida, Barcelona, Paidós [Trad. Albino Santos Mosquera].

BEACCO, J.-C. (1992) : Un Lieu d'inscription de la didacticité : les catastrophes naturelles dans la presse quotidienne, París, Presses de la Sorbonne Nouvelle.

Edwards, D.; N. Mercer (1988): El conocimiento compartido: el desarrollo de la comprensión en el aula, Barcelona, Paidós.

KARMILOFF-SMITH,A. (1992): Beyond modularity: a developmental perspective on cognitive science, Cambridge, Bradford Books.

MerCer, N. (1997): La construcción guiada del conocimiento. El habla de profesores y alumnos, Barcelona, Paidós.

Monferrer, A.; V. Salvador (2012): «Procediments discursius de la divulgació científica en l'àmbit periodístic: l'èxit mediàtic de la maleïda partícula de Higgs», Journal of Catalan Studies, 128-150.

Morin, E. (1994): Introducción al pensamiento complejo, México, Gedisa [Trad. Marcelo Pakman].

SAlvador, V. (2000): «Portal: discurs científic i comunicació social» en Saber i comunicar, monográfico del Anuari de l'Agrupació Borrianenca de Cultura, 11: 5-11.

- (2004): «La difusió social dels sabers científics: pràctiques i comunitats discursives» en La llengua i laliteratura: historia i actualitat. Actes de les jornades celebrades a la Universitat Jaume I en el setantè aniversari de les Bases Ortogràfiques del 1932, Barcelona/Castelló, Institut d'Estudis Catalans / Universitat Jaume I, 97-101.

Vygotsky, L. S. (1995): Pensamiento y lenguaje, Barcelona, Paidós. 